\title{
Homocystinuria Due to MTHFR Variant Presenting As Infantile Tremor Syndrome
}

\author{
Vykuntaraju K. Gowda' ${ }^{1}$ (D) Varunvenkat M. Srinivasan ${ }^{2} \cdot$ Sanjay K. Shivappa $^{2}$
}

Received: 30 April 2021 / Accepted: 13 July 2021 / Published online: 4 August 2021

(c) Dr. K C Chaudhuri Foundation 2021

To the Editor: Infantile tremor syndrome (ITS) is characterized by tremors, anemia, skin depigmentation, and developmental delay [1]. We are reporting a case of homocystinuria presenting as ITS.

An 8-mo-old boy presented with developmental delay and tremors for 3 mo. The child was on exclusive breast-feeding till 6 mo of age, and later weaned on ragi malt. The mother was on vegetarian diet. The child attained partial neck control and social smile by $7 \mathrm{mo}$, and following upper respiratory tract infection, there was a loss of above milestones. On examination, microcephaly (head size: $39 \mathrm{~cm}, z$ score: -4.78 ), weight of $6.9 \mathrm{~kg}$ ( $z$ score: -2.31$)$, hypopigmented hair, pallor, hypotonia, brisk deep-tendon reflexes and tremors involving hands and tongue, complete head lag, and no social smile were observed.

On investigation, hemoglobin was $8.5 \mathrm{~g} / \mathrm{dL}$, megaloblastic anemia on peripheral smear with normal total leukocyte and platelets counts. Serum vitamin B12 was low - 180.5 (normal: 211-911 pg/mL), homocysteine was high - 127.05 (3-50 micromol/L), and urine methylmalonic acid level was normal. MRI of brain showed cerebral atrophy. The child was treated with vitamin-B12 $1000 \mu \mathrm{g}$ intravenous daily for $14 \mathrm{~d}$ followed by intramuscular twice weekly and nutritional rehabilitations. Repeat serum homocysteine after $1 \mathrm{mo}, 2 \mathrm{mo}$, and 3 mo were 88,80 , and $75 \mathrm{micromol} / \mathrm{L}$, respectively. Hence, considered possibility of inherited homocystinuria and exome sequencing revealed compound heterozygous variant in MTHFR gene. The variant-1 was c.1129 C>T/p.R377C in exon 7 and variant-2 was c.767 T>A/p.I256N in exon 5. Later, the child was treated with pyridoxine, folic acid, betaine, and special formula diet. Clinical improvement was noted at 12 mo of age with complete attainment of head control and social smile.

Vykuntaraju K. Gowda

drknvraju08@gmail.com

1 Department of Pediatric Neurology, Indira Gandhi Institute of Child Health, Bengaluru, Karnataka 560029, India

2 Department of Pediatrics, Indira Gandhi Institute of Child Health, Bengaluru, Karnataka, India
The child had features of ITS, but despite treatment there was persistent homocysteinemia. Hence, after further evaluation, the child was diagnosed as MTHFR deficiency. Both the variants were described earlier [2,3]. The pathogenic variants in MTHFR gene may cause secondary vitamin B12 deficiency [4]. To conclude, homocystinuria due to MTHFR deficiency should be considered when ITS is not improving, and persistent homocysteinemia as the treatment and prognosis are different.

\section{Declarations}

Conflict of Interest None.

\section{References}

1. Kalra V. Infantile tremor syndrome. In: Ghai OP, editor. Essential Pediatrics. 7th ed. New Delhi: CBS Publishers and Distributions Pvt. Ltd.; 2009. p. 558-9.

2. Goyette P, Christensen B, Rosenblatt DS, Rozen R. Severe and mild mutations in cis for the methylenetetrahydrofolate reductase (MTHFR) gene, and description of five novel mutations in MTHFR. Am J Hum Genet. 1996;59:1268-75.

3. Burda P, Schäfer A, Suormala T, et al. Insights into severe 5, 10- methylenetetrahydrofolate reductase deficiency: molecular genetic and enzymatic characterization of 76 patients. Hum Mutat. 2015;36:611-21.

4. Al-Batayneh KM, Zoubi MSA, Shehab M, et al. Association between MTHFR 677C $>$ T polymorphism and vitamin B12 deficiency: a casecontrol study. J Med Biochem. 2018;37:141-7.

Publisher's Note Springer Nature remains neutral with regard to jurisdictional claims in published maps and institutional affiliations. 